\title{
Primary care provider payment models and adherence to anticoagulation in patients with atrial fibrillation
}

Lanting Yang, MPH; Jingchuan Guo, MD, PhD; Qingfeng Liang, MS, MA; Terri V Newman, PharmD, MS; Walid F Gellad, MD, MPH; and Inmaculada Hernandez, PharmD, PhD

\section{What is already known about this subject}

- Only $50 \%-60 \%$ of US patients with atrial fibrillation use anticoagulation in stroke prevention, and fewer adhere to therapy over time.

- Suboptimal anticoagulation use is associated with poor clinical outcomes.

\section{What this study adds}

- Receipt of care from a practice enrolled in a shared-savings payment model was associated with $7 \%$ higher odds of adherent use of oral anticoagulation.

- The odds of adherence to oral anticoagulation increased over time from 2015 to 2018.

\section{ABSTRACT}

BACKGROUND: Oral anticoagulation (OAC) is recommended for the prevention of stroke in atrial fibrillation (AF). However, only $50 \%$ $60 \%$ of AF patients in the United States are treated with $\mathrm{OAC}$, and $60 \%$ of them adhere to OAC therapy over time.

OBJECTIVES: To (1) compare adherent use of OAC between AF patients who received primary care from practices involved in shared-savings models and patients who received care from practices not involved in shared savings and (2) examine the trend of adherence to OAC over time. Because OAC can save downstream medical costs associated with averted stroke events, we hypothesized that OAC adherence would be higher among patients receiving care from practices involved in shared savings.

METHODS: Using 2014-2019 claims data from a health insurer in western Pennsylvania, we identified 20,637 AF patients from 20152018. Patients were followed from the first

\begin{abstract}
Author affiliations
Lanting Yang, MPH, and Terri V Newman, PharmD, MS, Department of Pharmacy and Therapeutics, University of Pittsburgh, Pittsburgh, PA. Jingchuan Guo, MD, PhD, Department of Pharmaceutical Outcomes \& Policy, University of Florida, Gainesville. Qingfeng Liang, MS, MA, UPMC Center for High-Value Health Care, Pittsburgh, PA. Walid F Gellad, MD, MPH, Division of General Internal Medicine, Department of Medicine, University of Pittsburgh, Pittsburgh, PA. Inmaculada Hernandez, PharmD, PhD, Division of Clinical Pharmacy, Skaggs School of Pharmacy and Pharmaceutical Sciences, University of California, San Diego.
\end{abstract}

AUTHOR CORRESPONDENCE:

Lanting Yang, 412.330.9432; lay26@pitt.edu

J Manag Care Spec Pharm. 2021;27(12):1672-79

Copyright (C2021, Academy of Managed Care Pharmacy. All rights reserved.

AF diagnosis (index date) for 12 months or until disenrollment. We categorized patients according to the payment model of the practice from which they received primary care: shared savings $(n=8,844)$ and no shared savings ( $n=11,793$ ). The primary outcome was adherent use of OAC therapy, which was defined as having at least $80 \%$ of the followup period covered with OAC. Secondary outcomes included adherent use of direct oral anticoagulants (DOACs) and adherent use of warfarin. We constructed logistic 
regression models to assess the association between involvement in shared savings and adherent use of OAC, while controlling for demographics, clinical characteristics, and index year.

RESULTS: $34 \%$ of patients in the shared-savings group adhered to OAC, compared with $32.7 \%$ in the no shared-savings group $(P=0.04)$. After adjustment, adherence was higher for the shared-savings group for OAC (adjusted odds ratio [aOR] $=1.07,95 \% \mathrm{Cl}=1.01-1.14$ ) and warfarin $(\mathrm{aOR}=1.11,95 \% \mathrm{Cl}=1.02-1.20)$ compared with the no shared-savings group. However, the odds of adherent use of DOACs did not statistically differ between shared savings and no shared savings ( $\mathrm{aOR}=0.99,95 \% \mathrm{Cl}=0.91-1.08)$. The odds of adherent OAC use increased over time: the aOR of adherent use of OAC was $1.21(95 \%$ $\mathrm{Cl}=1.09-1.34)$ for index year $2016 ; 1.50(95 \% \mathrm{Cl}=1.36-1.67)$ for 2017 ; and 1.78 (95\% Cl 1.60-1.98) for 2018, all compared with 2015.

CONCLUSIONS: Receipt of primary care from a practice involved in shared savings was associated with a higher adherent use of OAC and warfarin for patients with atrial fibrillation. Furthermore, adherent use of OAC improved over time for both treatment groups. Our research demonstrates that the alignment of financial incentives between providers and insurers may improve the use of therapies with downstream cost-saving potential. system financial incentives as one of the strategies most likely to mitigate OAC underuse..$^{10,13}$ This proposal rested on the premise that OAC can save downstream medical costs associated with averted stroke events; thus, payment models that align financial incentives between insurers and providers should incentivize the prescribing of OAC. ${ }^{11}$ However, to our knowledge, no studies have formally tested this hypothesis.

To address this evidence gap, we examined data from a regional insurer in western Pennsylvania and compared OAC use between AF patients receiving primary care from practices involved in shared-savings models and patients who received care from practices not involved in shared savings. Shared savings is a payment model that offers providers savings if they reduce health care spending for a group of patients defined by specific quality measures. Because OAC can save downstream medical costs associated with averted stroke events, we hypothesized that OAC adherence would be higher among patients receiving care from practices involved in shared savings. As a secondary objective, we assessed trends in the adherent use of OAC over time.

\section{Methods}

Atrial fibrillation (AF) is the most common cardiac arrhythmia and affects 34 million individuals globally. ${ }^{1}$ It is estimated that 12 million people in the United States will have $\mathrm{AF}$ in $2030 .^{2} \mathrm{AF}$ is associated with a 5-fold increased risk of stroke. ${ }^{3}$ Oral anticoagulation (OAC) is recommended by professional society guidelines for $\mathrm{AF}$ patients with moderate to high stroke risk, which is defined as having a $\mathrm{CHA}_{2} \mathrm{DS}_{2}$-VASC score of 2 or more. ${ }^{4}$ However, only $50 \%-60 \%$ of $\mathrm{AF}$ patients recommended for $\mathrm{OAC}$ treatment actually use OAC and, among users, only $60 \%$ of them adhere to the treatment over time. ${ }^{5,6}$ Before the approval of direct oral anticoagulants (DOACs), underuse of OAC was mostly attributed to the multiple limitations of warfarin therapy. ${ }^{7,8}$ However, the recent availability of DOACs has only modestly improved OAC use. ${ }^{9}$ The suboptimal adherence of $\mathrm{OAC}$ is concerning because continuous adherence to OAC is crucial for stroke prevention in $\mathrm{AF}$-the missing of a single $\mathrm{OAC}$ dose is associated with an increased stroke risk. ${ }^{10}$ It has been estimated that increasing the optimal use of OAC by half would avert 20,000 stroke events annually and result in savings of $\$ 1.3$ million. ${ }^{11}$

In 2012, experts from academia, government, industry, and professional societies convened to identify barriers to OAC use and propose solutions to this major public health problem. ${ }^{12}$ This think tank proposed the implementation of provider payment models that align health care

\section{DATA SOURCES AND STUDY POPULATION}

We obtained 2014-2019 data from a regional health insurer in western Pennsylvania. We identified patients who were diagnosed with AF between January 1, 2015, and December 31, 2018. AF was defined as having 1 inpatient or 2 outpatient claims with International Classification of Diseases, Ninth Revision, Clinical Modification (ICD-9-CM) diagnosis code 427.31 or International Classification of Disease, Tenth Revision, Clinical Modification (ICD-10-CM) diagnosis codes I48.0, I48.1, I48.2, and I48.91. ${ }^{14}$ The date of the first AF diagnosis in 2015-2018 was the index date. We then excluded patients who had a prescription filled for OAC in the year before the index date. To ensure availability of complete data to define covariates and the OAC washout period, we constrained sampling to patients continuously enrolled in the 12 months before the index date. Patients or disenrollment.

Our study sample included patients newly diagnosed with AF regardless of whether an OAC prescription was ever filled. We did not constrain for OAC initiators because the study objective was to investigate whether AF patients who received primary care from practices involved in shared-saving models are associated with higher adherent use of OAC but not OAC users. The inclusion of patients who were followed from index date for 12 months or until death 


\begin{tabular}{|c|c|c|c|}
\hline Variables $^{\mathrm{a}}$ & $\begin{array}{c}\text { No shared-savings } \\
\text { model } \\
(n=11,793)\end{array}$ & $\begin{array}{c}\text { Shared-savings } \\
\text { model } \\
(n=8,844)\end{array}$ & Pvalue $^{b}$ \\
\hline \multicolumn{4}{|l|}{ Age, years } \\
\hline$<60$ & $2,517 \quad(21.3)$ & $1,638 \quad(18.5)$ & \multirow{3}{*}{$<0.001$} \\
\hline $60-80$ & $6,370 \quad(54.2)$ & $4,906 \quad(55.5)$ & \\
\hline$>80$ & $2,906 \quad(24.6)$ & $2,300 \quad(26.0)$ & \\
\hline \multicolumn{4}{|l|}{ Sex } \\
\hline Male & $6,435 \quad(54.6)$ & $4,701 \quad(53.2)$ & \multirow{2}{*}{0.044} \\
\hline Female & $5,358 \quad(45.4)$ & $4,143 \quad(46.8)$ & \\
\hline \multicolumn{4}{|l|}{ Llinical characteristics } \\
\hline Chronic kidney disease & $2,591 \quad(22.0)$ & $2,026 \quad(22.9)$ & 0.110 \\
\hline Congestive heart failure & $2,648 \quad(22.5)$ & $1,723 \quad(19.5)$ & $<0.001$ \\
\hline Diabetes & $3,746 \quad(31.8)$ & $2,582 \quad(29.2)$ & $<0.001$ \\
\hline History of any bleeding & $2,029 \quad(17.2)$ & $1,501 \quad(17.0)$ & 0.660 \\
\hline Hypertension & $7,568 \quad(64.3)$ & $5,570 \quad(63.0)$ & 0.047 \\
\hline Ischemic stroke & $1,282 \quad(10.9)$ & $944 \quad(10.7)$ & 0.652 \\
\hline Liver disease & $453 \quad(3.84)$ & $(3.94)$ & $<0.001$ \\
\hline Myocardial infarction & $587 \quad(5.0)$ & $(5.3)$ & 0.346 \\
\hline Peripheral vascular disease & $2,605 \quad(22.1)$ & $2,027 \quad(22.9)$ & 0.157 \\
\hline Substance use disorder & $594 \quad(5.0)$ & $(5.7)$ & 0.226 \\
\hline Thromboembolism & $435 \quad(3.7)$ & (3.4) & 0.255 \\
\hline Valvular heart disease & $526 \quad(4.5)$ & (3.4) & $<0.001$ \\
\hline Use of antiplatelet & $1,277 \quad(10.8)$ & $894 \quad(10.1)$ & 0.095 \\
\hline Use of NSAIDS & 1,076 & (8.9) & 0.656 \\
\hline
\end{tabular}

never initiated $\mathrm{OAC}$ is of importance, since poor initiation and suboptimal adherence to OAC are major barriers to improved outcomes in AF.

This study was approved by the Institutional Review Board at the University of Pittsburgh as exempt because deidentified data were used in analyses.

\section{EXPOSURE}

Each study participant was assigned to a primary practice as follows: (1) patients who had selected their primary care providers (PCPs; 33\% of sample) were attributed to the eligible for savings generated by reduced spending incurred by their patients if they meet certain quality standards. At the time of this study, the shared-savings program evaluated 12 metrics based on Centers for Medicare \& Medicaid Services star ratings and HEDIS scores, none of which specifically measured anticoagulation use. ${ }^{15}$ We hypothesized that practices involved in the sharedsavings program would be incentivized to prescribe OAC because they would benefit from reductions in health care spending associated with averted strokes.

\section{OUTCOMES}

The primary outcome was adherent use of OAC, which was defined as having at least $80 \%$ of the follow-up period with possession of OAC. For each patient, we extracted all prescriptions for OAC, including warfarin, apixaban, dabigatran, and rivaroxaban, that were filled after the index date (date of first AF diagnosis). Using the fill dates and the days supply, we created a drug diary and calculated the number of days that patients had possession of OAC during the follow-up period. Adherent use of OAC equaled 1 for patients who had at least $80 \%$ of the follow-up period with possession of $\mathrm{OAC}$, and equaled 0 otherwise. When a claim was refilled before the previous fill should have run out, we assumed that the use of the new fill started after the end of the previous fill. The OAC drug diary did not account for hospitalization days.

Secondary outcomes included adherent use of warfarin and adherent use of DOACs and were defined similarly to the primary outcome, except using prescriptions for warfarin or DOACs, respectively. This methodology has been previously used to examine adherent use of OAC. ${ }^{10,16,17}$ Defining medication exposure using pharmacy claims data has 


\section{TABLE 1}

\section{Baseline Patic
(continued)}

\begin{tabular}{|c|c|c|c|}
\hline Variables $^{\mathrm{a}}$ & $\begin{array}{c}\text { No shared-savings } \\
\text { model } \\
(n=11,793)\end{array}$ & $\begin{array}{c}\text { Shared-savings } \\
\text { model } \\
(n=8,844)\end{array}$ & P value $^{b}$ \\
\hline \multicolumn{4}{|l|}{ Social determinants } \\
\hline $\begin{array}{l}\text { Area Deprivation Index score, }{ }^{c} \\
\text { mean (SD) }\end{array}$ & 107.7 & 105.4 & $<0.001$ \\
\hline \multicolumn{4}{|l|}{ Insurance type } \\
\hline Commercial & $2,684 \quad(22.8)$ & $2,058 \quad(23.3)$ & \multirow{3}{*}{$<0.001$} \\
\hline Medicaid & $1,034 \quad(8.8)$ & $(6.2)$ & \\
\hline Medicare & $8,075 \quad(68.5)$ & $6,242 \quad(70.6)$ & \\
\hline Patients who had PCP selected & $3,701 \quad(31.4)$ & $3,161 \quad(35.8)$ & $<0.001$ \\
\hline \multicolumn{4}{|l|}{ Index year } \\
\hline 2015 & $6,536 \quad(55.4)$ & $4,050 \quad(45.8)$ & \multirow{4}{*}{$<0.001$} \\
\hline 2016 & $2,135 \quad(18.1)$ & $1,486 \quad(16.8)$ & \\
\hline 2017 & $1,757 \quad(14.9)$ & $1,618 \quad(18.3)$ & \\
\hline 2018 & $1,365 \quad(11.6)$ & $1,690 \quad(19.1)$ & \\
\hline
\end{tabular}

Note: Data in table are presented as $n(\%)$, unless otherwise indicated.

${ }^{a}$ All characteristics were evaluated at index date.

bP value was estimated using Student's t-tests for continuous variables and chi-square tests for categorical variables.

'The Area Deprivation Index is a validated measure that quantifies socioeconomic factors of granular census block. ${ }^{26}$

dPatients who had selected their PCPs were attributed to the reported PCP; patients with no PCP selected according to the health insurer records were matched to a practice using an algorithm that incorporates such parameters as provider identifier, tax identification number, provider ZIP code, and health plan type of the claims in the previous 24 months.

NSAID = nonsteroidal anti-inflammatory drug; $P C P=$ primary care provider.

\begin{tabular}{|c|c|c|c|c|c|}
\hline & Outcomes & $\begin{array}{c}\text { No shared-savings } \\
\text { model } \\
(n=11,793)\end{array}$ & $\begin{array}{r}\text { Shared- } \\
\text { mo } \\
(n=8\end{array}$ & $\begin{array}{l}\text { savings } \\
\text { del } \\
844)\end{array}$ & $P$ value \\
\hline \multirow{3}{*}{$\begin{array}{l}\text { dherent use } \\
\text { f OAC, }{ }^{a} \\
(\%)\end{array}$} & Use of OAC & $3,853 \quad(32.7)$ & 3,008 & $(34.0)$ & 0.04 \\
\hline & Use of warfarin & $2,214 \quad(18.8)$ & 1,568 & $(17.7)$ & 0.06 \\
\hline & Use of DOAC & $1,531 \quad(13.0)$ & 1,349 & $(15.3)$ & $<0.001$ \\
\hline
\end{tabular}

${ }^{a}$ Adherent use was defined as having $\geq 80 \%$ of the follow-up period with possession of OAC. $D O A C=$ direct oral anticoagulants; $O A C=$ oral anticoagulation .

been reported to have sensitivity over $90 \% .^{18,19}$

\section{COVARIATES}

Baseline covariates included demographics, social determinants, clinical characteristics, and index year. Demographic characteristics included age group and sex. Social determinants included area deprivation index, insurance type, and whether the patient had a selected primary care provider. Clinical characteristics included chronic kidney disease, congestive heart failure, diabetes, hypertension, ischemic stroke, liver disease, myocardial infraction, peripheral vascular disease, substance use disorder, thromboembolism, valvular heart disease, history of any bleeding, gastrointestinal bleeding, intracranial bleeding, and use of antiplatelet and nonsteroidal anti-inflammatory drugs. Index year was defined as the year patients had the first AF diagnosis. The definition of covariates has been published previously. ${ }^{20}$

\section{STATISTICAL ANALYSIS}

We compared patient characteristics between shared-savings and no shared-savings groups using Student's t-tests for continuous variables and chi-square tests for categorical variables. We used multivariable logistic regression models to examine the association between receipt of care from a practice involved in shared savings and adherent use of OAC. Stepwise selection was performed for covariate selection (Supplementary Table 1, available in online article). The index year was included in the model to estimate the odds of adherent use of OAC over time. The predicted probability of adherent use over time that estimated with logistic regression models was reported. P values less than 0.05 were considered statistically significant.

We performed sensitivity analyses after excluding patients who had selected a PCP. We performed a second set of sensitivity analyses among patients who did not have a diagnosis of valvular disease in the year before the index date. We performed a third set of sensitivity analyses after applying a washout period with no diagnosis of $\mathrm{AF}$ in the 12 months before the index date. The subcohort selected in 


\section{FIGURE 1 Adjusted Odds Ratios for Adherent Use: Shared-Savings Group vs No Shared-Savings Group}

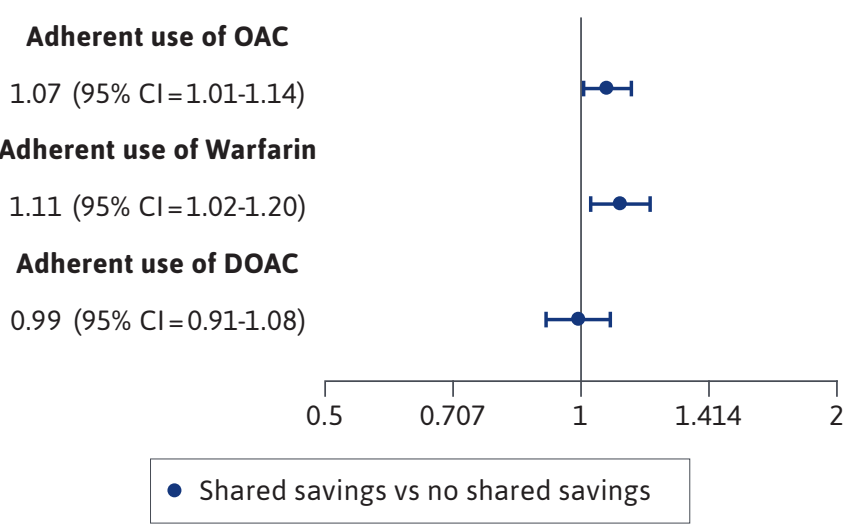

Note: Adherent use was defined as having $\geq 80 \%$ of the follow-up period with possession of OAC.

$D O A C=$ direct oral anticoagulants; $O A C=$ oral anticoagulation

this third set of sensitivity analyses represented incident (newly diagnosed) AF patients.

\section{Results}

\section{BASELINE PATIENT CHARACTERISTICS}

Patients who received primary care from a practice enrolled in a shared-savings program were older and more likely to be enrolled in Medicare (Table 1). However, there were no statistically significant differences in the proportion of patients with chronic kidney disease, history of bleeding, ischemic stroke, or myocardial infraction between the 2 groups. Patients in the shared-savings group were more likely to have 2017 and 2018 (as opposed to 2015 and 2016) as index years, which reflected the increased uptake of this novel payment model over time.

\section{ADHERENT USE OF OAC BY TREATMENT GROUP}

Table 2 shows the descriptive statistics for the adherent use of OAC, warfarin, and DOACs. For the shared-savings group, $34.0 \%$ of patients adhered to OAC, compared with $32.7 \%$ in the no shared-savings group $(P=0.04)$. For the shared-savings group, $15.3 \%$ of patients adhered to DOACs, compared with $13.0 \%$ in the no shared-savings group $(\mathrm{P}<0.001)$. The descriptive statistics for the proportion of follow-up time covered with OAC, warfarin, and DOACs are shown in Supplementary Table 2 (available in online article).

\section{ADJUSTED RESULTS FOR THE ASSOCIATION BETWEEN RECEIPT OF CARE FROM A PRACTICE INVOLVED IN SHARED SAVINGS AND ADHERENT USE OF OAC}

Figure 1 shows the adjusted odds ratios (aOR) of adherent use of OAC, warfarin, and DOACs for patients receiving primary care from a practice involved in shared savings vs patients receiving care from practices not involved in shared savings. Adherent use of OAC $(\mathrm{aOR}=1.07,95 \%$ $\mathrm{CI}=1.01-1.14)$ and adherent use of warfarin $(\mathrm{aOR}=1.11,95 \%$ $\mathrm{CI}=1.02-1.20)$ were higher for the shared-savings group compared with the no shared-savings group. However, the odds of adherent use of DOACs did not statistically differ between shared savings and no shared savings $(\mathrm{aOR}=0.99$, $95 \% \mathrm{CI}=0.91-1.08)$. Results from sensitivity analyses were consistent with the primary findings (Supplementary Table 3 , available in online article).

\section{TIME TRENDS IN ADHERENT USE OF OAC}

After adjustment, the odds of adherent use of OAC increased over time. Specifically, the aOR of adherent use of OAC were 1.21 (95\% CI=1.09-1.34) for index year 2016; $1.50(95 \%$ $\mathrm{CI}=1.36-1.67)$ for index year 2017; and $1.78(95 \% \mathrm{CI}=1.60-1.98)$ for index year 2018, all compared with 2015 (Figure 2). The odds of adherent use of DOACs followed a similar trend, increasing over time. The odds of adherent use of warfarin, however, decreased over time (Figure 2).

Figure 3 shows the estimated probability of adhering to $\mathrm{OAC}$, DOACs, and warfarin for each calendar year, based on the output from the logistic regression models. The adjusted estimated probability of adherent use of OAC increased from $28.8 \%$ in 2015 to $41.8 \%$ in 2018, after adjusting for selected covariates. The same trend was observed for adherent use of DOACs (Figure 3).

\section{Discussion}

To our knowledge, this study is the first to assess the association between shared-savings payment models and adherent use of OAC in AF patients. We found that receipt of care from a practice enrolled in a shared-savings model was associated with $7 \%$ higher odds of adherent use of OAC and $11 \%$ higher odds of adherent use of warfarin. We found a substantial improvement in adherent use of OAC over time: After adjusting for patient characteristics, the odds of adherent use of OAC were 78\% higher in 2018 than 2015.

Our estimates for adherent use of OAC are in line with previous literature that estimated the rate of adherent use of OAC at around $40 \% .^{9,19}$ The improved adherent use of OAC and DOACs observed over time is also consistent with previous research. ${ }^{21-23}$ Although our study is the first to test the 


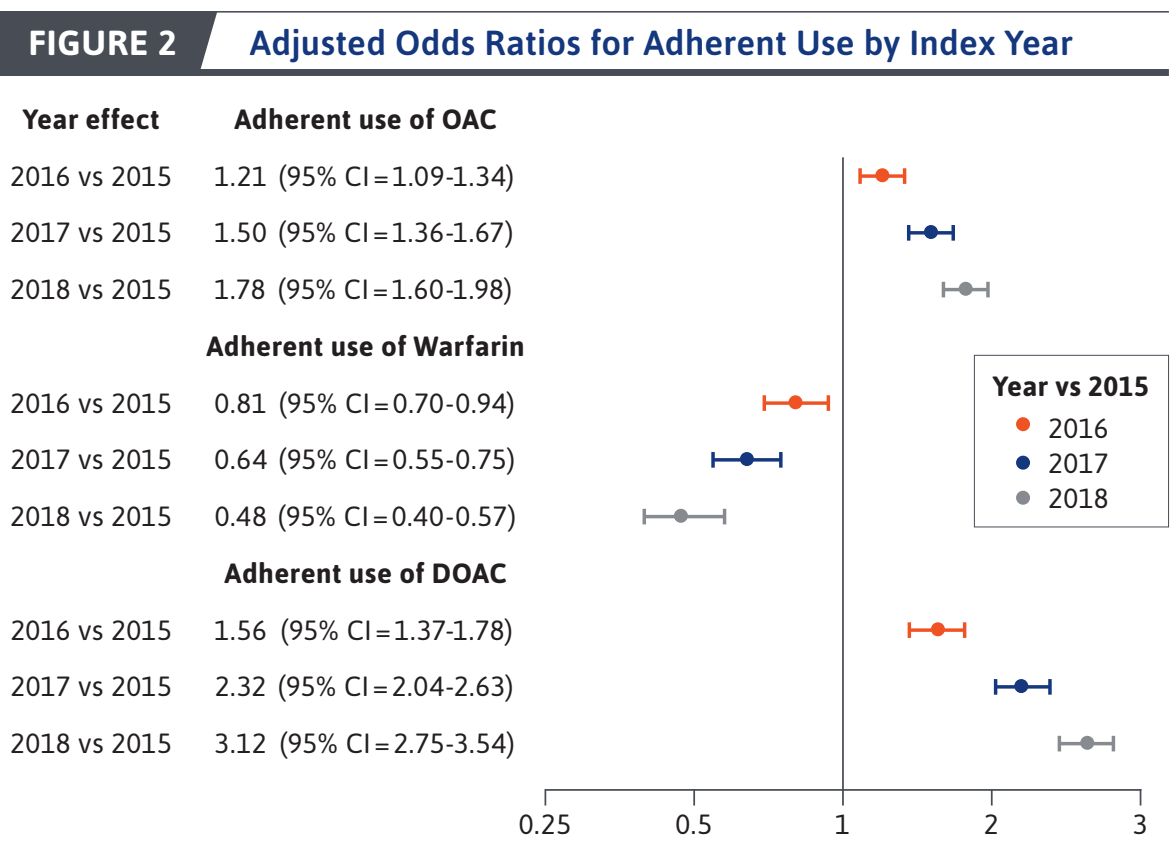

Note: Adherent use was defined as having $\geq 80 \%$ of the follow-up period with possession of OAC. $D O A C=$ direct oral anticoagulants; $O A C=$ oral anticoagulation . whether patients took medications as indicated. Thus, our outcomes represent medication possession, and we were not able to distinguish between patients who were not prescribed OAC by their providers and those who were prescribed OAC but did not fill prescriptions.

Second, claims data do not capture prescriptions not covered through insurance, such as warfarin obtained through \$4 generic programs or samples obtained from physician offices. This could have resulted in an underestimation of adherent $\mathrm{OAC}$ use rates but should not differ between our 2 exposure groups.

Third, although we controlled for a comprehensive list of patient characteristics, our results may have still been subject to selection bias. For example, it is possible that healthy adherers were more likely to visit providers who were fast adopters of new payment models and thus more likely to be involved in a sharedsavings program.

Fourth, the data source, like all claims data, did not have detailed clinical information such as body weight or international normalized ratio levels.

Fifth, we were not able to constrain for $\mathrm{AF}$ patients with a $\mathrm{CHA}_{2} \mathrm{DS}_{2}-\mathrm{VASc}$ score of 2 or more because of unavailability of a continuous variable for age due to data security requirements. Nevertheless, we controlled for the clinical components of $\mathrm{CHA}_{2} \mathrm{DS}_{2}-$ VASc score and for categorical age in our models.

Sixth, we constructed 2 separate models to examine the associations between shared-savings models and adherence to DOAC and warfarin. Switching between therapies could have led to an underestimation of adherence rates because, when examining the outcome of DOAC use, for instance, the days covered with warfarin would not have been counted. 


\section{FIGURE 3 Estimated Probability of Adherent Use of Oral Anticoagulation by Index Year}

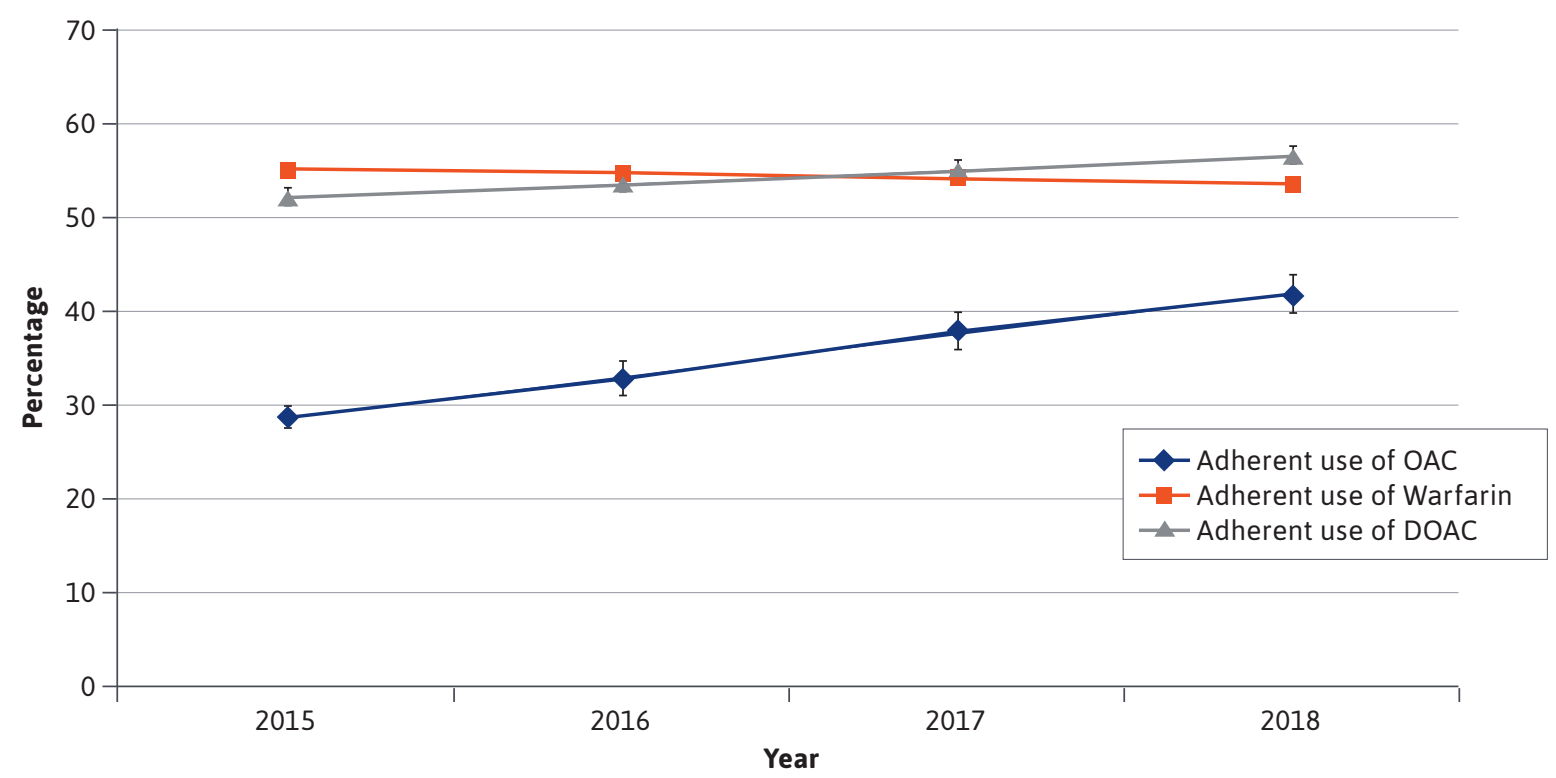

\begin{tabular}{c|r|r|r|r}
\hline Year & \multicolumn{2}{|c|}{ Adherent use of OAC } & Adherent use of Warfarin & \multicolumn{2}{c}{ Adherent use of DOAC } \\
\hline 2015 & $28.8(27.7-29.9)$ & $55.0(54.8-55.2)$ & $52.1 \quad(52.0-52.3)$ \\
\hline 2016 & $32.8(31.1-34.5)$ & $54.6(54.2-54.9)$ & $53.5(53.2-53.8)$ \\
\hline 2017 & $37.9(36.0-39.7)$ & $54.1(53.8-54.4)$ & $55.0(54.7-55.3)$ \\
\hline 2018 & $41.8 \quad(39.9-53.8)$ & $53.6(53.3-54.0)$ & $56.4(56.1-56.7)$ \\
\hline
\end{tabular}

Note: Adherent use was defined as having $\geq 80 \%$ of the follow-up period with possession of OAC. Data in table is presented as probability of OAC adherent use and $95 \% \mathrm{Cl}$.

$D O A C=$ direct oral anticoagulants; $O A=$ oral anticoagulation .

Switching, however, would not have affected our overall rate of adherence to OAC.

Finally, our study sample was limited to beneficiaries from 1 insurer, so our findings cannot be generalized to the entire population of AF patients, particularly, because the design of shared-savings models may differ vastly across insurers.

\section{Conclusions}

In this retrospective cohort study, we found that receipt of care from a practice involved in shared savings was associated with a modest increase in adherent use of OAC and warfarin. Adherent use of OAC substantially improved from 2015 to 2018. Our findings suggest that provider payment models that align financial incentives may encourage the use of high-value medications with costsaving potential.

\section{DISCLOSURES}

This project was funded by the National Heart, Lung and Blood Institute (grant number K01HL142847). Hernandez has received consulting fees from Pfizer and BMS, outside of the submitted work. The other authors have nothing to disclose.

\section{REFERENCES}

1. Dai H, Zhang Q, Much AA, et al. Global regional, and national prevalence, incidence, mortality, and risk factors for atrial fibrillation, 1990-2017: results from the Global Burden of Disease Study 2017. Europ Heart J Qual Care Clin Outcomes. July 31, 2020. Epub ahead of print. doi:10.1093/ehjqcco/qcaa061

2. Colilla S, Crow A, Petkun W, Singer DE, Simon T, Liu X. Estimates of current and future incidence and prevalence of atrial fibrillation in the U.S. adult population. Am J Cardiol. 2013;112(8):1142-47. doi:10.1016/j.amjcard.2013.05.063

3. Hart RG, Halperin JL. Atrial fibrillation and stroke : concepts and controversies. Stroke. 2001;32(3):803-08. doi:10.1161/01. str.32.3.803 
4. January CT, Wann LS, Alpert JS, et al. 2014 AHA/ACC/HRS guideline for the management of patients with atrial fibrillation: executive summary. Circulation. 2014;130(23):2071-104. doi:10.1161/ CIR.0000000000000040

5. Lang K, Bozkaya D, Patel AA, et al. Anticoagulant use for the prevention of stroke in patients with atrial fibrillation: findings from a multi-payer analysis. BMC Health Serv Res. 2014;14:329. doi:10.1186/1472-6963-14-329

6. Ogilvie IM, Newton N, Welner SA, Cowell W, Lip GY. Underuse of oral anticoagulants in atrial fibrillation: a systematic review. Am J Med. 2010;123(7):638-45.e4. doi:10.1016/j. amjmed.2009.11.025

7. Fang MC, Go AS, Chang Y, et al. Warfarin discontinuation after starting warfarin for atrial fibrillation. Circ Cardiovasc Qual Outcomes. 2010;3(6): 624-31. doi:10.1161/circoutcomes.110. 937680

8. Maura G, Pariente A, Alla F, Billionnet C. Adherence with direct oral anticoagulants in nonvalvular atrial fibrillation new users and associated factors: a French nationwide cohort study. Pharmacoepidemiol Drug Saf. 2017;26(11):1367-77. doi:10.1002/ pds.4268

9. Yao X, Abraham NS, Alexander GC, et al. Effect of adherence to oral anticoagulants on risk of stroke and major bleeding among patients with atrial fibrillation. J Am Heart Assoc. 2016;5(2):e003074. doi:10.1161/jaha.115.003074

10. Hernandez I, He M, Brooks MM, Saba S, Gellad WF. Adherence to anticoagulation and risk of stroke among medicare beneficiaries newly diagnosed with atrial fibrillation. Am J Cardiovasc Drugs. 2020;20(2):199-207. doi:10.1007/ s40256-019-00371-3

11. Caro JJ. An economic model of stroke in atrial fibrillation: the cost of suboptimal oral anticoagulation. Am J Manag Care. 2004;10(14 Suppl):S451-58.

12. Hess PL, Mirro MJ, Diener HC, et al. Addressing barriers to optimal oral anticoagulation use and persistence among patients with atrial fibrillation: proceedings, Washington, DC, December 3-4, 2012. Am Heart J. Sep 2014;168(3):239-247. e1. doi: 10.1016/j.ahj.2014.04.007
13. Peterson ED, Pokorney SD. New treatment options fail to close the anticoagulation gap in atrial fibrillation. J Am Coll Cardiol. 2017;69(20):2485-87. doi:10.1016/j.jacc.2017.03.541

14. Centers for Medicare \& Medicaid Services. Chronic Conditions Data Warehouse. Condition categories. Accessed July 13, 2020. https:// www2.ccwdata.org/web/guest/ condition-categories

15. UPMC Health Plan. UPMC Health Plan shared savings program and bundled payment pilot. Presented at: CMS LAN Summit. April 26, 2016. Accessed August 6, 2021. https://lansummit.org/wp-content/uploads/ sites/9/2016/04/2E_Case-StudiesFrom-Provider-Led-OrganizationsImplementing-APMS_Sweeney.pdf

16. Chen SY, Wu N, Gulseth M, et al. One-year adherence to warfarin treatment for venous thromboembolism in high-risk patients and its association with long-term risk of recurrent events. J Manag Care Pharm. 2013;19(4):291-301. doi:10.18553/jmcp.2013.19.4.291

17. McHorney CA, Ashton V, Laliberté F, et al. Adherence to rivaroxaban compared with other oral anticoagulant agents among patients with nonvalvular atrial fibrillation. J Manag Care Spec Pharm. 2017;23(9):980-88. doi:10.18553/ jmcp.2017.23.9.980

18. Lau HS, de Boer A, Beuning KS, Porsius A. Validation of pharmacy records in drug exposure assessment. J Clin Epidemiol. 1997;50(5):619-25. doi:10.1016/ s0895-4356(97)00040-1

19. Rodríguez-Bernal CL, García-Sempere A, Hurtado I, Santa-Ana Y, Peiró S, Sanfélix-Gimeno G. Real-world adherence to oral anticoagulants in atrial fibrillation patients: a study protocol for a systematic review and meta-analysis. BMJ Open. 2018;8(12):e025102. doi:10.1136/ bmjopen-2018-025102
20. Hernandez I, He M, Chen N, Brooks MM, Saba S, Gellad WF. Trajectories of oral anticoagulation adherence among Medicare beneficiaries newly diagnosed with atrial fibrillation. J Am Heart Assoc. 2019;8(12):e011427. doi:10.1161/jaha.118.011427

21. Perreault S, de Denus S, White-Guay B, et al. Oral anticoagulant prescription trends, profile use, and determinants of adherence in patients with atrial fibrillation. Pharmacotherapy. 2020;40(1):40-54. doi:10.1002/phar.2350

22. Weitz JI, Semchuk W, Turpie AG, et al. Trends in prescribing oral anticoagulants in Canada, 2008-2014. Clin Ther. 2015;37(11):2506-14.e4. doi:10.1016/j. clinthera.2015.09.008

23. Martinez C, Katholing A, Wallenhorst C, Freedman SB. Therapy persistence in newly diagnosed nonvalvular atrial fibrillation treated with warfarin or NOAC. A cohort study. Thromb Haemost. 2016;115(1):31-39. doi:10.1160/ th15-04-0350

24. McWilliams JM, Najafzadeh M, Shrank WH, Polinski JM. Association of changes in medication use and adherence with accountable care organization exposure in patients with cardiovascular disease or diabetes. JAMA Cardiol. 2017;2(9):1019-23. doi:10.1001/ jamacardio.2017.2172

25. Parekh N, Munshi KD, Hernandez I, Gellad WF, Henderson R, Shrank WH. Impact of star rating medication adherence measures on adherence for targeted and nontargeted medications. Value Health. 2019;22(11):1266-74. doi:10.1016/j. jval.2019.06.009

26. Kurani S, McCoy RG, Inselman J, et al. Place, poverty and prescriptions: a crosssectional study using Area Deprivation Index to assess opioid use and drugpoisoning mortality in the USA from 2012 to 2017. BMJ Open. 2020;10(5):e035376. doi:10.1136/bmjopen-2019-035376 